\title{
CARACTERIZAÇÃO DOS ACIDENTES COM TRATORES AGRÍCOLAS
}

\author{
CHARACTERIZATION OF THE ACCIDENTS INVOLVING \\ AGRICULTURAL TRACTORS
}

\author{
José Fernando Schlosser ${ }^{1}$ Henrique Debiasi ${ }^{2}$ \\ Geovano Parcianello ${ }^{3}$ Lisandro Rambo ${ }^{3}$
}

RESUMO

Em despeito à sua importância, poucas pesquisas vêm sendo executadas com o intuito de caracterizar os acidentes de trabalho com tratores agrícolas, identificando sua natureza (tipo) bem como suas causas. $O$ objetivo deste trabalho foi caracterizar os acidentes envolvendo tratores agrícolas ocorridos na região da Depressão Central do Rio Grande do Sul e, a partir disto, delinear estratégias eficientes na sua prevenção. Para o levantamento dos dados, foi aplicado um questionário aos operadores de tratores agrícolas da região da Depressão Central do Rio Grande do Sul. Os dados demonstraram que $39 \%$ dos trabalhadores rurais entrevistados já sofreram algum tipo de acidente de trabalho com tratores agrícolas. Dentre os tipos de acidentes com tratores agrícolas detectados na pesquisa, destacam-se o capotamento, que correspondeu a $51,71 \%$ do total de acidentes graves, e os escorregões, que corresponderam a 40,82\% dos acidentes leves. As principais causas dos acidentes relatados foram a falta de conhecimento a respeito das medidas de segurança na operação de tratores (32,77\%), a falta de atenção (32,22\%) para a tarefa executada e o equipamento inadequado $(22,22 \%)$. Os acidentes graves tiveram causas diferentes comparativamente aos leves. Operadores sem treinamento adequado, a não observação de regras básicas de segurança e a longa jornada de trabalho são tendências observadas neste trabalho que ampliam os riscos de ocorrência de acidentes. A inclusão de dispositivos que tornem a máquina mais segura e confortável, bem como o treinamento dos operadores de tratores agrícolas são práticas de importância fundamental para a prevenção dos acidentes com tratores agrícolas.

Palavras-chave: tipos de acidentes, causas dos acidentes, prevenção.
SUMMARY

Despite its importance, few researches have been carried out characterizing work accidents involving agricultural tractors. The objective of this work was to characterize the accidents with agricultural tractors, to determine more efficient ways to prevent them. A questionnaire was applied to an ample of agricultural tractor operators from the Central Region of Rio Grande do Sul State. Results showed that 39\% of the agricultural tractor operators analyzed had already suffered some kind of accident. The most frequent type of serious accidents was tractor overturning which occurred in $51.71 \%$ of the cases. Slips were the most important slight accident. The most important causes of accidents were lack of knowledge about safety procedures on tractor operation (32.77\%), lack of attention (32.22\%) to the task carried out and inadequate equipment $(22.22 \%)$. There were great differences between the causes of serious and slight accidents. Operators without adequate training, no observation of some important safety procedures and very long working day were reported in this research, collaborating to increase the occurrence of accidents. Finally, it is necessary to incorporate confort and security devices, as well as training the agricultural tractor operators, to prevent future accidents.

Key words: kind of accidents, causes of accidents, prevention.

\section{INTRODUÇÃO}

Uma das principais consequiências da modernização da agricultura brasileira foi a substituição progressiva do trabalho manual pelo trabalho mecanizado. A introdução de instrumentos

\footnotetext{
${ }^{1}$ Professor Titular, Doutor, Engenheiro Agrônomo, Departamento de Engenharia Rural, Centro de Ciências Rurais (CCR), Universidade Federal de Santa Maria (UFSM), Campus Universitário, Camobi, 97105-900, Santa Maria, RS. E-mail: schlosse@ccr.ufsm.br. Autor para correspondência.

${ }^{2}$ Professor Substituto, Engenheiro Agrônomo, Departamento de Engenharia Rural, CCR, UFSM.

${ }^{3}$ Engenheiro Agrônomo, Mestrando do Programa de Pós-graduação em Agronomia, Universidade Federal do Rio Grande do Sul. 
e insumos modernos nas tarefas agrícolas ampliou significativamente os tipos de acidentes de trabalho a que estão sujeitos os trabalhadores rurais (RODRIGUES \& DA SILVA, 1986). Se antes os acidentes de trabalho no meio rural estavam restritos basicamente a quedas, ferimentos com ferramentas de trabalho (enxada, facão) e envenenamentos causados por animais peçonhentos, a manipulação de agrotóxicos e a utilização intensa de máquinas agrícolas ampliou consideravelmente os riscos a que estão sujeitos os trabalhadores rurais em seu trabalho diário.

Segundo o artigo 131 do Decreto $\mathrm{n}^{\mathrm{o}}$ 2.172, de 05 de março de 1997, acidente de trabalho no meio rural é o que ocorre na realização do trabalho rural, a serviço do empregador, provocando lesão corporal, perturbação funcional ou doença que cause a morte ou redução permanente ou temporária da capacidade para o trabalho. De uma maneira geral, conforme expõem ZÓCCHIO (1971) e UNESP (1994), o acidente de trabalho no meio rural pode ser considerado como sendo todo o acontecimento que não esteja programado e que interrompa, por pouco ou muito tempo, a realização de um serviço, provocando perda de tempo, danos materiais e/ou lesão corporal. Neste sentido, o acidente é considerado grave quando resulta no afastamento do trabalhador rural de sua atividade produtiva por um período igual ou superior a 15 dias (UNESP, 1994).

Dentre todos os acidentes de trabalho que ocorrem no meio rural, merecem destaque os que envolvem tratores agrícolas. Segundo MÁRQUEZ (1986), na Espanha e nos demais países europeus, aproximadamente $40 \%$ do total de acidentes ocorridos no setor agrário envolvem máquinas agrícolas e, destes, metade são devido ao uso do trator agrícola. Em uma pesquisa de caracterização dos acidentes graves no trabalho rural, realizada no Estado de São Paulo, SILVA \& FURLANI NETO (1999) concluíram que o trator, a motosserra, as máquinas e os equipamentos agrícolas não definidos encontram-se envolvidos na maior parte dos acidentes graves ocorridos.

Os prejuízos econômicos e sociais advindos dos acidentes com tratores agrícolas também são bastante elevados. Estes ocorrem tanto em termos de danos físicos ao operador como em termos financeiros, para o Estado, sociedade em geral e para o próprio acidentado.

No que se refere aos danos físicos aos trabalhadores, MÁRQUEZ (1986) explica que mais de $60 \%$ das mortes ocorridas em acidentes de trabalho no setor agrário são conseqüência da mecanização agrícola. A gravidade dos acidentes com tratores agrícolas é confirmada por FIELD (2000), que, em trabalho realizado no Estado de Indiana, nos Estados Unidos da América, encontrou dados que demonstram que, entre 500 e 600 pessoas morrem a cada ano naquele país em função de acidentes com tratores agrícolas e que a cada pessoa morta, outras 40, no mínimo, são feridas.

Em relação aos custos financeiros dos acidentes, MONK et al. (1986) expõem que os gastos anuais com os acidentes de trabalho na agricultura para a economia britânica chegam à cifra de 94 milhões de dólares por ano. Os dados obtidos por MÁRQUEZ (1990) reforçam a magnitude dos custos dos acidentes. Segundo o referido autor, o ônus dos acidentes na Europa chega a aproximadamente 5 bilhões de dólares.

A caracterização dos acidentes com tratores agrícolas reveste-se de grande importância, porque diferentes tipos de acidentes (capotamento, quedas a distinto nível, atropelamentos, entre outros) possuem causas e conseqüências específicas (MÁRQUEZ, 1986). Portanto, acidentes de diferentes tipos exigem práticas, na maioria das vezes, específicas para a efetiva minimização de seu nível de ocorrência e gravidade. No que se refere às causas, ZÓCCHIO (1971), ALONÇO (1999) e CARDELLA (1999) definem dois grandes grupos de causas de acidentes de trabalho: atitudes inseguras e condições inseguras. O primeiro grupo relaciona-se diretamente às falhas humanas, enquanto o segundo engloba as limitações inerentes à maquina. Neste sentido, MÁRQUEZ (1990) indica que, na Espanha, $84 \%$ dos acidentes com tratores agrícolas são causados por atitudes inseguras.

Assim, o objetivo deste trabalho foi caracterizar os acidentes envolvendo tratores agrícolas na região da Depressão Central do Rio Grande do Sul, através da determinação de seus tipos e causas predominantes, a fim de se obter subsídios para delinear estratégias eficientes na sua prevenção.

\section{MATERIAL E MÉTODOS}

O levantamento dos dados referentes a este trabalho abrangeu uma amostra de 123 operadores de tratores agrícolas pertencentes à região da Depressão Central do Estado do Rio Grande do Sul. A amostragem foi do tipo aleatória simples (SCHEAFFER $\boldsymbol{e t}$ al., 1996). A determinação do tamanho da amostra seguiu a metodologia exposta por STORCK et al. (2000), através da execução de um levantamento piloto, que, no caso desta pesquisa, englobou 20 operadores. Através deste levantamento piloto, foi obtido coeficiente de 
variação (CV \%) para cada variável, o qual foi usado para o cálculo do tamanho da amostra:

$$
\mathrm{N}=\underline{\mathrm{t}_{\alpha / 2}} \frac{2}{\mathrm{~d}^{2}}
$$

onde:

$\mathrm{N}=$ Número de elementos a serem amostrados; $\mathrm{t}_{\propto / 2}=$ valor tabelado da distribuição de $\mathrm{t}$, com $\propto$ probabilidade de erro $(5 \%)$ e GL $=\mathrm{n}-1$ graus $\mathrm{de}$ liberdade, sendo $\mathrm{n}$ o número de elementos amostrados no levantamento piloto; $\mathrm{CV}=$ Coeficiente de variação, em \%; d = Margem de erro em relação à média $(10 \%)$.

Posteriormente, foi escolhido o maior tamanho de amostra entre os calculados para cada variável. Assim, determinou-se que o tamanho mínimo da amostra deveria ser de 110 operadores.

A cada operador foi aplicado um questionário englobando perguntas que visavam à detecção do envolvimento ou não do operador em algum acidente com trator agrícola e, em caso de resposta afirmativa, à caracterização do acidente sofrido. As características dos acidentes avaliadas foram o tipo e as causas. Cabe destacar que o tipo de acidente corresponde à forma como este ocorreu, ao passo que as causas constituem-se em atos e condições inseguras que propiciam a ocorrência de acidentes (ZÓCCHIO, 1971; ALONÇO 1999 e CARDELLA 1999). Ainda, os acidentes foram separados em graves ou leves, usando como critério o tempo de afastamento do operador. $\mathrm{O}$ acidente foi considerado grave quando o tempo de afastamento do trabalho foi superior a 15 dias.

Além de dados a respeito dos acidentes com tratores agrícolas, foram reportadas, através do mesmo questionário, algumas características referentes ao operador entrevistado, as quais influem na ocorrência dos acidentes de trabalho com este tipo de máquina: participação em cursos de treinamento na operação de tratores agrícolas, adoção de procedimentos seguros (uso do cinto e proibição de caroneiros junto ao trator) e duração da jornada de trabalho, nas épocas de maior demanda de trabalho, haja visto a sazonalidade das atividade agrícolas.

Os questionários foram elaborados com alternativas previamente definidas de resposta (questionário fechado). A opção por este tipo de questionário justifica-se pela maior facilidade na organização e tabulação dos dados, comparativamente aos questionários com perguntas "abertas" (sem alternativas previamente definidas).
A análise dos dados obtidos neste trabalho foi efetuada através da aplicação dos recursos da estatística descritiva. Os dados reportados pelos questionários foram organizados $\mathrm{e}$ tabulados $\mathrm{e}$, posteriormente, as freqüências absolutas foram transformadas em freqüências relativas (\%) e dispostas em gráficos para a apresentação dos resultados.

\section{RESULTADOS E DISCUSSÃO}

A primeira análise refere-se ao grau de incidência dos acidentes com tratores agrícolas. Segundo os dados obtidos neste trabalho, 39\% dos operadores entrevistados já haviam sofrido algum tipo de acidente, leve ou grave, com tratores agrícolas. Estes dados reforçam as conclusões obtidas por MÁRQUEZ (1986) e SILVA \& FURLANI NETO (1999), que em seus trabalhos indicaram o trator agrícola como sendo a máquina responsável por cerca de $20 \%$ acidentes de trabalho na agricultura.

Conforme é apresentado na figura 1, na região da Depressão Central do Rio Grande do Sul, o acidente grave de maior ocorrência foi $o$ capotamento do trator, englobando $51,71 \%$ dos casos relatados. Já no que se refere aos acidentes leves (Figura 2), o tipo mais freqüente foram os escorregões, correspondendo a mais de $40 \%$ dos acidentes reportados. Verifica-se também que os acidentes leves e graves diferiram entre si no que se refere ao tipo. Apenas o contato com partes ativas da máquina foi relatado tanto para os acidentes graves

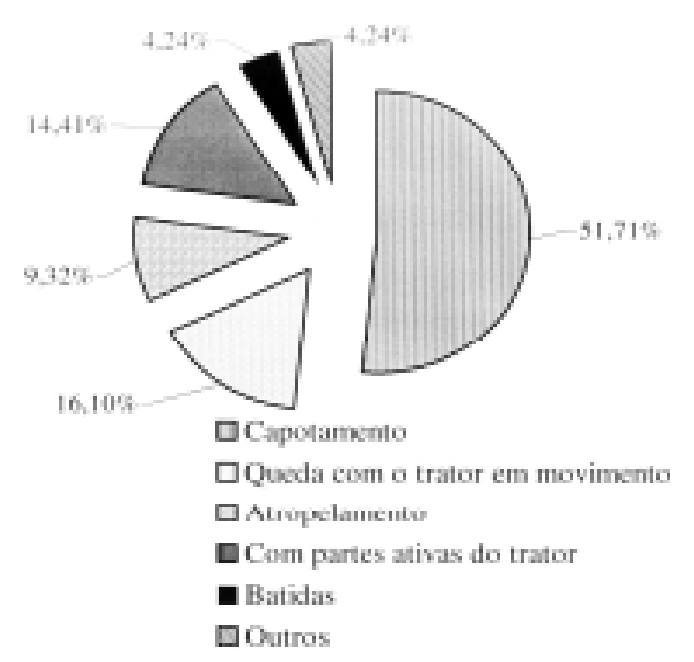

Figura 1 - Principais tipos de acidentes graves envolvendo tratores agrícolas. 


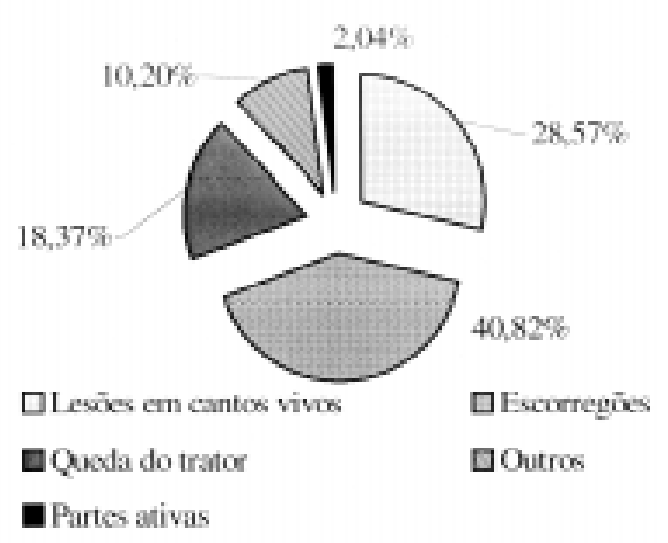

Figura 2 - Principais tipos de acidentes leves envolvendo tratores agrícolas.

quanto para os leves. Assim, pode-se inferir que os acidentes leves e graves ocorrem de maneira diferente e, portanto, exigem medidas de prevenção específicas.

A determinação dos principais tipos de acidente graves e leves, conforme exposto anteriormente, torna possível a detecção das causas dos mesmos. Conhecendo-se as causas, pode-se atuar no sentido de eliminá-las, de forma a prevenir eficientemente os acidentes com tratores agrícolas. As principais causas dos acidentes de trabalho envolvendo tratores agrícolas relatados pelos entrevistados são apresentadas na figura 3.

É possível agrupar as causas (Figura 3) segundo os dois grandes grupos de condicionantes de acidentes, ou seja, em atos inseguros e condições inseguras (ZÓCCHIO, 1971; ALONÇO 1999 e CARDELLA 1999). Assim, verifica-se que a maior parte dos acidentes $(78,78 \%)$ são ocasionados por atos inseguros, o que é obtido pela soma das porcentagens das causas específicas falta de atenção,

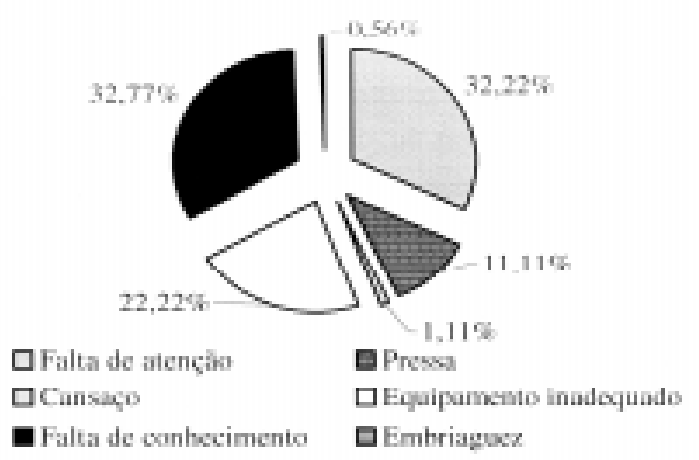

Figura 3 - Principais causas dos acidentes com tratores agrícolas. cansaço, falta de conhecimento, pressa e embriaguez. Dados semelhantes foram obtidos por MÁRQUEZ (1990). Por outro lado, apenas 22,22\% dos acidentes relatados na pesquisa são creditados a limitações relacionadas ao equipamento (trator). Entretanto, é imprescindível ter em mente a interação entre as causas dos acidentes. Conforme WITNEY (1988), a falta de atenção e o cansaço, que resultam em atos inseguros, têm sua gênese também explicada pela ação indireta do trator que, devido a problemas em suas características ergonômicas (conforto), pode resultar no aumento da fadiga do operador.

A falta de conhecimento, apontada como uma das principais causas dos acidentes, pode ser explicada pelo fato de a maior parte dos operadores $(60,74 \%)$ não terem freqüentado algum curso de operação de tratores agrícolas, que desse ênfase, além dos aspectos de produtividade do trabalho, à segurança. Um exemplo típico da falta de conhecimento em relação à prevenção dos acidentes com tratores agrícolas é a elevada porcentagem $(66,34 \%)$ de operadores que permitem que pessoas andem de "carona" no trator. Esta atitude pode resultar em quedas de pessoas com o trator em movimento, um dos principais tipos de acidentes graves, conforme foi explicado anteriormente.

Outro produto da falta de conhecimento e, também, da falta de condições de segurança nos tratores agrícolas atualmente em uso no Brasil refere-se ao cinto de segurança. Os dados obtidos apontam que $61,11 \%$ dos tratores em uso na região de abrangência desta pesquisa não possuem cinto de segurança. Com relação aos tratores que possuem cinto de segurança, em cerca de $69 \%$ dos casos os operadores não o usam. Cabe salientar que a presença e uso do cinto de segurança é requisito obrigatório para o tráfego dos tratores agrícolas em rodovias, segundo o Capítulo IX, Seção I, artigo 96 do Código de Trânsito Brasileiro (Lei 9.503, de 23 de setembro de 1997). Além disso, os dados obtidos mostram que, muitas vezes, os tratores são equipados com estruturas de proteção contra capotamento, mas o operador não usa o cinto, de forma que sua eficiência praticamente é anulada.

A falta de atenção é outra importante causa dos acidentes com tratores agrícolas. Esta têm sua origem em função, dentre outros fatores, da operação de tratores ergonomicamente mal projetados e de aspectos ligados à jornada de trabalho, que podem aumentar de maneira substancial o nível de fadiga ao qual o operador encontra-se submetido. Isto resulta numa diminuição de sua capacidade de concentração, o que pode resultar em acidentes (WITNEY, 1988). Pôde-se 
observar que $67,65 \%$ dos operadores entrevistados têm uma jornada de trabalho superior a 8 horas durante os períodos de maior demanda de trabalho, que correspondem, normalmente, às épocas de preparo do solo, semeadura ou colheita. Portanto, a longa jornada de trabalho em determinados períodos pode explicar, em grande parte, o elevado número de acidentes observados na região.

$\mathrm{Na}$ figura 3 são apresentadas as principais causas dos acidentes em geral, ou seja, considerando conjuntamente os acidentes graves e leves. Porém, verifica-se que os acidentes graves e leves diferem entre si com relação às suas causas. $\mathrm{O}$ equipamento inadequado, segundo os dados obtidos na região da Depressão Central, parece ser a principal causa direta dos acidentes leves, sendo responsável por $54 \%$ dos referidos acidentes, conforme é demonstrado na tabela 1. Isto é justificado em função de que os acidentes leves, via de regra, ocorrem devido a detalhes inadequados das máquinas, como por exemplo, a presença de superfícies contundentes e a inexistência de superfícies antiderrapantes. Já no que se refere aos acidentes graves, a principal causa direta apontada foi a falta de atenção, sendo responsável por aproximadamente $40 \%$ dos acidentes. Entretanto, no caso dos acidentes graves, o equipamento inadequado influiu indiretamente, pois máquinas ergonomicamente mal projetadas colaboram para um aumento do cansaço do operador e, em consequiência, diminuem a capacidade de concentração. A segunda principal causa, para ambos os acidentes, é a falta de conhecimento, embora este item seja mais importante no caso dos acidentes graves. Assim, pode-se deduzir que a prevenção dos acidentes com tratores agrícolas deve-se centrar, basicamente, no oferecimento de cursos de treinamento aos operadores, bem como no projeto de máquinas ergonomicamente corretas e seguras, o que poderá resultar numa drástica redução da ocorrência de acidentes, tanto leves quanto graves.

Tabela 1 - Causa dos acidentes graves e leves com tratores agrícolas (valores em portagem).

\begin{tabular}{lcc}
\hline \multirow{2}{*}{ Causas } & \multicolumn{2}{c}{ Tipo de acidente } \\
\cline { 2 - 3 } & Graves & Leves \\
\hline Falta de atenção & 40,80 & 12,10 \\
Pressa & 14,80 & 06,60 \\
Cansaço & 00,00 & 9,10 \\
Equipamento inadequado & 14,80 & 54,00 \\
Falta de conhecimento & 18,50 & 15,20 \\
Embriaguez & 03,70 & 00,00 \\
Outros & 07,40 & 03,00 \\
Total & 100,0 & 100,0 \\
\hline
\end{tabular}

\section{CONCLUSÃO}

Os acidentes com tratores agrícolas graves e leves diferiram entre si no que se refere ao tipo e as causas. Para os mais graves, o tipo mais freqüente é o capotamento, sendo causados normalmente pela falta de conhecimento em relação às regras de segurança e pela falta de atenção na tarefa que está sendo executada. Para os acidentes leves, o tipo mais comum foram os escorregões, sendo causados na maioria das vezes por limitações inerentes ao equipamento.

A inclusão de dispositivos que tornem o trator mais confortável e seguro, o treinamento dos operadores e a redução da jornada de trabalho são estratégias necessárias à redução da incidência de acidentes com este tipo de máquina.

\section{REFERÊNCIAS BIBLIOGRÁFICAS}

ALONÇO, A. dos S. Noções de segurança e operação de tratores. In: REIS, A.V. dos, MACHADO, A.L.T., TILLMANN, C.A. da C., et al. Motores, tratores, combustíveis e lubrificantes. Pelotas : Universitária, 1999. Cap.4, p.221230 .

CARDELLA, B. Segurança no trabalho e prevenção de acidentes: uma abordagem holística: segurança integrada à missão organizacional com produtividade, qualidade, preservação ambiental e desenvolvimento de pessoas. São Paulo: Átlas, 1999. 254p.

FIELD, B. Safety with farm tractors. Indiana : Cooperative Extension Service, Purdue University, 2000. 10p. (Bulletin S-56).

MÁRQUEZ, L. Maquinaria agrícola y seguridad vial. Boletim Salud y Trabajo, Madrid, n.56, 6p. 1986.

MÁRQUEZ, L. Solo tractor’90. Madrid: Laboreo, 1990. Cap.4: Ergonomía y seguridad en los tractores agrícolas: p.146-207.

MONK, A.S., MORGAN, D.D.V., MORRIS, J., et al. The cost of accidents in agriculture. Journal of Agricultural Engeneering Research, Silsoe, v.33, p.245-257, 1986.

RODRIGUES, V.L.G.S., DA SILVA, J.G. Acidentes de trabalho e modernização da agricultura brasileira. Revista Brasileira de Saúde Ocupacional, v.14, n.56, p.28-39, 1986.

SCHEAFFER, R.L., MENDENHALL III, W., Ott, L. Elementary survey sampling. 5. ed. USA : IPT, 1996. p.126-195.

SILVA, J.R., FURLANI NETO, V.L. Acidentes graves no trabalho rural: II - Caracterização. In: CONGRESSO BRASILEIRO DE ENGENHARIẢ AGRÍCOLA, 28, 1999, Pelotas, RS. Anais.... Pelotas : Sociedade Brasileira de Engenharia Agrícola, 1999. CD-Room.

STORCK, L.; LOPES, S.J.; LÚCIO, A.D. Introdução à experimentação. Santa Maria : UFSM, 2000. 49p.

UNESP. Prevenção e controle de riscos em máquinas. Bauru: Faculdade de Engenharia e Tecnologia, 1994. 165p. Apostila.

ZÓCCHIO, A. Prática da prevenção de acidentes: $\mathrm{ABC}$ da segurança do trabalho. 2. ed. São Paulo : Atlas, 1971. 173p.

WITNEY, B. Choosing and using farm machines. Harlow : Longman Scientific and technical, 1998. p.28-94. 